\title{
Produção de sementes pré-básicas de batata em sistemas hidropônicos.
}

\author{
Carlos Alberto B. Medeiros ${ }^{1}$; Alisson Hofstatter Ziemer ${ }^{2}$; Julio Daniels ${ }^{1}$; Arione S. Pereira ${ }^{1}$ \\ ${ }^{1}$ Embrapa Clima Temperado, C. Postal 403, 96.001-970, Pelotas-RS. E-mail: medeiros@cpact.embrapa.br; ${ }^{2}$ UFLA, C. Postal 37, 37.200- \\ 000 Lavras-MG.
}

\section{RESUMO}

Os métodos convencionais de produção de sementes pré-básicas de batata apresentam como característica comum a reduzida eficiência, em razão dos baixos índices de multiplicação de tubérculos. A introdução de novos métodos de produção que propiciem maiores taxas de multiplicação podem contribuir para o aumento da disponibilidade de sementes de qualidade, e por conseqüência para a elevação da produtividade da cultura. Nesse trabalho são descritos dois sistemas hidropônicos, que pelos resultados obtidos, revelam sua viabilidade para a produção de sementes pré-básicas, com aumentos significativos nos índices de multiplicação, e que podem representar um importante avanço no processo produtivo de sementes de batata.

\begin{abstract}
Production of potato pre-basic seeds in hydroponic systems.

The reduced tuber multiplication rate determines the low efficiency in the conventional methods of potato pre-basic seed production. New methods of seed production, with higher multiplication rates, may contribute to improve yield by increasing the availability of good quality seeds. This study describes two hydroponic systems, suitable for growing potato pre-basic seeds, which may represent an important step in the production process of potato seeds.
\end{abstract}

Keywords: Solanum tuberosum L., soilless culture.

\section{(Aceito para publicação em 07 de fevereiro de 2.002)}

\begin{abstract}
A utilização de material propagativo de alta qualidade fitossanitária, é requisito indispensável para a obtenção de elevadas produtividades na cultura da batata. Doenças transmissíveis por semente, como viroses e a murcha bacteriana, constituem-se em fatores limitantes da produtividade, ocasionando em muitas regiões elevados prejuízos. Levantamento da incidência de viroses em áreas de produção de batatasemente a partir de material pré-básico, nas principais regiões produtoras dos Estados de Santa Catarina e do Rio Grande do Sul, revelam índices de infecção de até $35 \%$ das plantas amostradas, atingindo níveis de $42 \%$ no caso específico de algumas cultivares (Daniels et al., 2000b). A primeira estratégia para o controle das doenças transmitidas via semente, tem sido o plantio de materiais sadios, oriundos de cultura de tecidos, onde a limpeza clonal e posterior indexação asseguram a qualidade fitossanitária do material produzido (Fortes et al., 1998). Essa técnica tem permitido, ganhos significativos de produtividade no cultivo da batata. $\mathrm{O}$ sucesso dessa estratégia, entretanto, depende, principalmente, de métodos eficientes de produção de material
\end{abstract}

propagativo, ou seja, de técnicas que propiciem multiplicações rápidas, e com custos reduzidos. Sob esse aspecto, os sistemas tradicionais de produção de sementes pré-básicas até então utilizados no Brasil, apresentam como característica comum, a reduzida eficiência, em razão dos baixos índices de multiplicação de tubérculos. São produzidos em média, nesses sistemas de três a cinco tubérculos por planta (Daniels et al., 2000a), o que contribui para a elevação dos custos da semente.

Nesse cenário, a introdução de novos métodos de produção de sementes pré-básicas que propiciem maiores taxas de multiplicação, seguramente representa um avanço na cadeia produtiva da batata, capaz de produzir reflexos positivos na produtividade, particularmente em regiões onde a qualidade das sementes utilizadas é fator limitante para a obtenção de maiores rendimentos. Dentre os novos métodos para a produção de batata semente, destacam-se as técnicas hidropônicas.

Diferentes sistemas hidropônicos vêm sendo empregados em diversos países, como forma de substituir os métodos convencionais de produção de tubérculos semente (Chang et al., 2000;
Romanenko, 1997), mas que nem sempre atingem os índices de multiplicação desejados (Le Hingrat \& Marhic, 1999). No Brasil, os resultados até então alcançados com a produção de tubérculos em sistemas hidropônicos (Medeiros et al., 2001a, 2001b; Pereira et al., 2001) revelam importante avanço no processo produtivo de sementes de batata, capaz de contribuir para a eliminação de um de seus pontos de estrangulamento: a baixa taxa de multiplicação de tubérculos pré-básicos.

A maior produtividade normalmente obtida nos sistemas hidropônicos, comparativamente ao cultivo tradicional, deve-se fundamentalmente à ausência de enfermidades radiculares, desde que utilizado material isento de patógenos, e ao melhor controle sobre a nutrição das plantas, através do uso de solução nutritiva adequada à espécie (Caldevilla \& Lozano, 1993). A solução permite manter junto às raízes a concentração desejada de nutrientes, procedendo-se os ajustes sempre que necessários. Da mesma forma, pode-se manter os valores de $\mathrm{pH}$ da solução em faixas pré estabelecidas, otimizando a absorção de nutrientes (Martínez \& Alvarez, 1993). 
Tabela 1. Número médio de tubérculos por planta e unidade de área e peso médio de tubérculos de batata cultivada em sistema hidropônico constituído de telhas de fibrocimento, em três espaçamentos. Pelotas, Embrapa Clima Temperado, 2001.

\begin{tabular}{lccc}
\hline Espaçamento & Tubérculos/planta & Tubérculos/m ${ }^{2}$ & $\begin{array}{c}\text { Peso médio de } \\
\text { tubérculos }(\mathbf{g})\end{array}$ \\
\hline $10 \mathrm{~cm}$ & $11,5 \mathrm{~b}^{*}$ & $513 \mathrm{a}$ & $14,6 \mathrm{a}$ \\
$15 \mathrm{~cm}$ & $12,6 \mathrm{ab}$ & $413 \mathrm{~b}$ & $16,3 \mathrm{a}$ \\
$20 \mathrm{~cm}$ & $14,3 \mathrm{a}$ & $339 \mathrm{~b}$ & $17,5 \mathrm{a}$ \\
\hline
\end{tabular}

Médias seguidas da mesma letra dentro de cada variável não diferem estatisticamente pelo teste de Duncan $(\mathrm{P}<0.05)$.

Esse trabalho tem como objetivo relatar resultados obtidos e descrever dois sistemas hidropônicos desenvolvidos na Embrapa Clima Temperado, para produção de sementes pré-básicas de batata.

\section{DESCRIÇÃO DOS SISTEMAS}

Nos sistemas desenvolvidos, a fonte de nutrientes é exclusivamente a solução nutritiva, podendo-se utilizar como material de multiplicação, minitubérculos ou plântulas micropropagadas, importantes quando for necessária a multiplicação de material proveniente da cultura de tecidos.

Sistema em telhas de fibrocimento

Nos primeiros estudos de produção de batata semente em plataforma de telha de fibrocimento, foram utilizados diferentes substratos (Medeiros \& Silva, 1999) em sistema de cultivo sem solo, que posteriormente evoluiu para o sistema atual, pela maior eficiência e facilidade de manejo. No sistema atualmente proposto, a colheita é realizada ao final do ciclo da cultura. Por essa razão, de forma semelhante às condições de campo, os tubérculos formados apresentam grande variabilidade de tamanho e peso, podendo atingir valores superiores a 250 g ou mesmo serem descartados pelo tamanho extremamente reduzido. Predominam entretanto tubérculos grandes (Classificação tipo I a III) o que indica esse sistema adequado para produção de tubérculos destinados a um subsequente plantio em condições de campo.

O sistema baseia-se em uma plataforma constituída de telhas de cimento amianto, com canais de $6 \mathrm{~cm}$ de altura e espaçados de $18 \mathrm{~cm}$ (distância entre dois pontos médios), recobertas por um filme de polietileno, assentadas sobre estrutura de madeira, a qual confere ao conjunto a declividade de $4 \%$. O revestimento com polietileno objetiva prevenir qualquer reação indesejável dos nutrientes da solução com o material constitutivo da telha, além de prevenir seu encharcamento. Os canais da telha são preenchidos com uma camada de granito fragmentado (brita) de tamanho médio, utilizado como auxiliar na sustentação das plantas. Sobre a brita é colocado outro filme de polietileno, cuja função é evitar a penetração da luz no sistema radicular das plantas em desenvolvimento. A incidência da luz sobre os estolões em formação, provoca seu esverdeamento, com emissão de folhas, reduzindo a tuberização. Esse segundo filme pode ser de polietileno preto ou preferencialmente de dupla face, para condições de intensa radiação e temperatura do ar elevada, contribuindo nesse caso, para redução da temperatura na zona de desenvolvimento das raízes e tubérculos. O plantio é realizado através de pequenos cortes em forma de cruz feitos nesse filme, por onde posteriormente, emergem os brotos e desenvolvem-se os caules.

Os estudos sobre espaçamento das plantas nesse sistema (Tabela 1) revelam seus efeitos diretos sobre o número de tubérculos produzidos. Espaçamentos menores, como no caso de $10 \mathrm{~cm}$ entre plantas, determinam maior número de tubérculos por unidade de área, com redução do número por planta, observando-se tendência de redução no tamanho médio dos tubérculos formados, em comparação àqueles desenvolvidos em espaçamentos maiores. Deve ser considerado, que o aumento da população de plantas determina maior percentagem de acamamento.

Quando a multiplicação é feita a partir de plântulas propagadas "in vitro", são utilizados pequenos cubos de esponja fenólica para dar sustentação ao caule da planta até que se complete a aclimatização. Melhores resultados em relação à sobrevivência têm sido obtidos com a aclimatização prévia das plântulas, antes do transplante para a estrutura hidropônica. Para tanto, as plântulas, já na esponja, são colocadas em bandejas com pequeno volume de solução nutritiva, protegidas contra temperatura e radiação elevadas, até que se complete a aclimatização, quando então são transferidas para a plataforma.

Sistema de Calhas de PVC articuladas (Figuras 1-4)

Sistema com princípios semelhantes a este, vêm sendo usado para produção de batata semente na Rússia (Romanenko, 1997). A estrutura constitui-se de duas calhas de PVC sobrepostas, sustentadas por suporte de madeira, posicionadas com declividade de $4 \%$. A calha superior, com função de tutoramento das plantas, é fixa com orifícios de $25 \mathrm{~mm}$ de diâmetro espaçados de 15 a $20 \mathrm{~cm}$. A inferior é móvel, podendo ser afastada e dessa forma expor os tubérculos em formação. Essa característica introduz o grande diferencial em relação ao sistema anterior, pois possibilita que os tubérculos sejam colhidos tão logo atinjam o tamanho desejado, o que torna o sistema apropriado à produção de minitubérculos. Na calha inferior, por onde circula a solução nutritiva e onde raízes e tubérculos se desenvolvem, é feito o plantio. Nessa ocasião, os minitubérculos ou plântulas micropropagadas são colocados em cubos de esponja fenólica e posicionados exatamente sob os orifícios existentes na calha superior. Os brotos ao crescerem passam através desses orifícios e as hastes de desenvolvem normalmente.

Como no caso anterior, a penetração da luz no sistema radicular das plantas deve ser evitada. Nessa estrutura, o ponto crítico de penetração de luz são as linhas de junção das duas calhas, onde os estolões tendem a forçar seu desenvolvimento para a parte externa. Uma fina lâmina de espuma sintética colocada entre as duas calhas, nas linhas de assentamento, minimiza a entrada de luz. Como medida complementar, utiliza-se uma cortina de filme de polietileno 
preto, com cerca de $25-30 \mathrm{~cm}$ de largura, presa nas bordas da calha superior, e que estende-se ao longo da linha de junção das calhas. Outra forma de restringir a entrada de luz é fixar um filme de polietileno preto ao longo da borda interna da calha superior, com ele envolver a calha inferior, prendendo-o na borda externa daquela calha. Quando necessário articular a calha inferior para a colheita, libera-se a parte fixada na borda externa.

\section{SOLUÇÃO NUTRITIVA}

\section{Composição}

Diferentes soluções nutritivas têm sido testadas, objetivando avaliar sua adequação aos sistemas hidropônicos desenvolvidos. Entre os resultados até então obtidos (Tabela 2), destacam-se aqueles onde utilizou-se a solução descrita por Furlani (1988) constituída de $\mathrm{N} 198\left(7: 1 \mathrm{NO}_{3}: \mathrm{NH}_{4}\right) ; \mathrm{P} 39 ; \mathrm{K} 183 ; \mathrm{Ca}$ 142; $\mathrm{Mg} 38 ; \mathrm{S} 52 ; \mathrm{Fe} 2,0 ; \mathrm{Mn} \mathrm{0,40;} \mathrm{Cu}$ 0,02; Zn 0,06; B 0,30; Mo 0,06 em mg $\mathrm{L}^{-1}$; a descrita por Clark (1982) modificada, constituída de N 360 (8:1 $\left.\mathrm{NO}_{3}: \mathrm{NH}_{4}\right) ; \mathrm{P} 12 ; \mathrm{K} 298 ; \mathrm{Ca} 302 ; \mathrm{Mg}$ 37,8; S 58,5; Fe 2,76; Mn 0,97; Cu 0,07; Zn 0,30; B 0,53; Mo 0,15 em $\mathrm{mg} \mathrm{L}^{-1}$; e a solução comercial constituída de $0,8 \mathrm{~g}$ $\mathrm{L}^{-1}$ de Kristalon Laranja ${ }^{\circledR}(6 ; 12 ; 36 ; 3 \mathrm{e}$ $8 \%$ de $\mathrm{N} ; \mathrm{P}_{2} \mathrm{O}_{5} ; \mathrm{K}_{2} \mathrm{O} ; \mathrm{MgO}$ e $\mathrm{S}$ respectivamente); $0,8 \mathrm{~g} \mathrm{~L}^{-1}$ Nitrato de cálcio Hydro ${ }^{\circledR}(16,5$ e $19 \%$ de $\mathrm{N}$ e Ca respectivamente) e $0,03 \mathrm{~g} \mathrm{~L}^{-1}$ de Tenso Cocktail ${ }^{\circledR}(2,57 ; 0,52 ; 0,13 ; 0,53 ; 2,1$; 1,74; 2,57 e $0,53 \%$ de Ca EDTA; B; Mo; $\mathrm{Cu}$ EDTA; Fe EDTA; Fe DTPA; Mn EDTA e Zn EDTA respectivamente).

Um aspecto importante para facilitar o manejo da solução nutritiva nos sistemas é a proporção entre o nitrogênio provido na forma nítrica e amoniacal. Essa proporção deve ser estabelecida de forma a não permitir grandes oscilações nos valores de $\mathrm{pH}$ da solução durante o desenvolvimento da cultura, o que determinaria a necessidade freqüente de correções, dificultando o manejo do sistema.

\section{Irrigações}

Em ambos sistemas descritos, a solução drenada é recirculada. As irrigações seguem uma programação cíclica, sendo a solução nutritiva bombeada durante quinze minutos, a cada intervalo

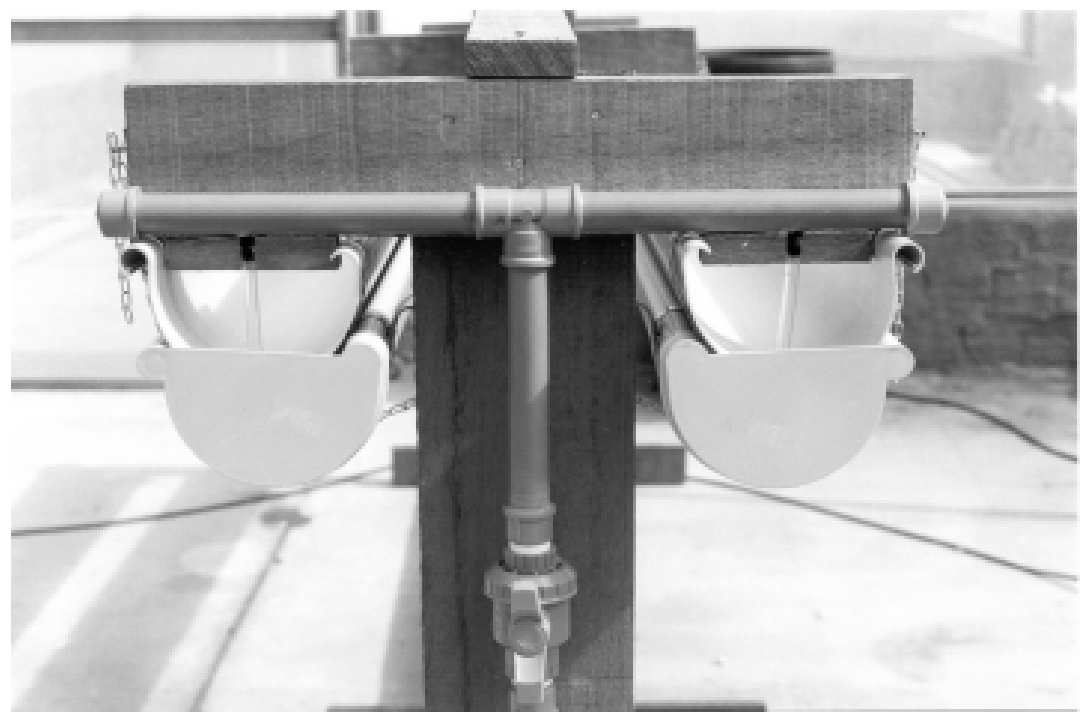

Figura 1. Conjunto de calhas com suporte

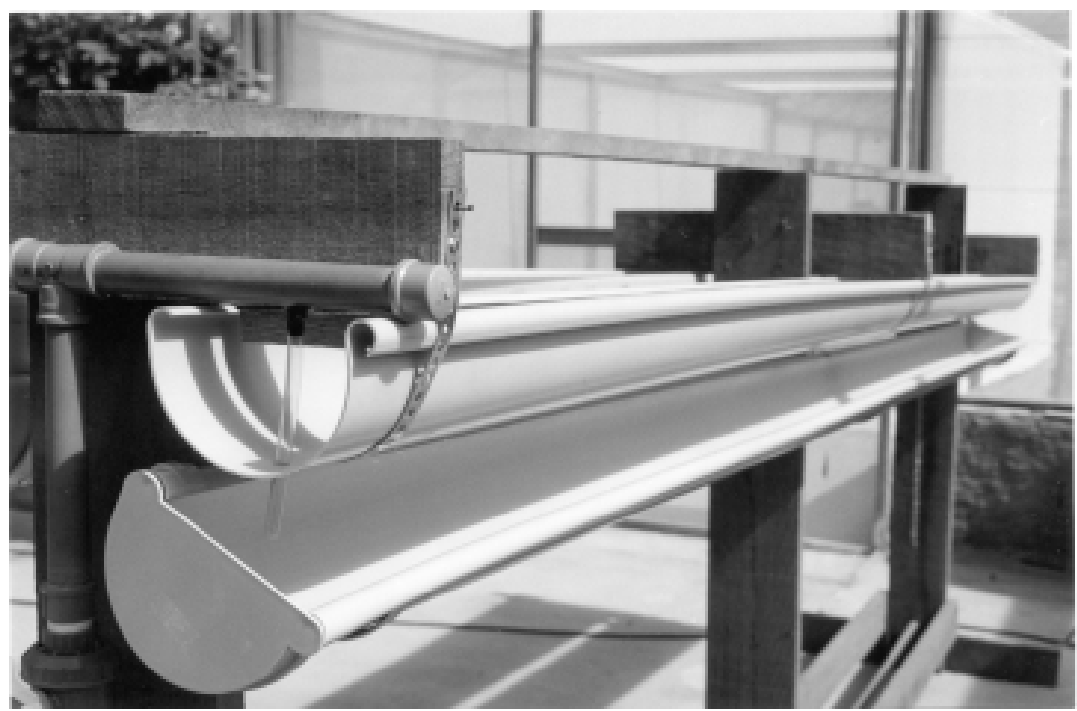

Figura 2. Calha articulada

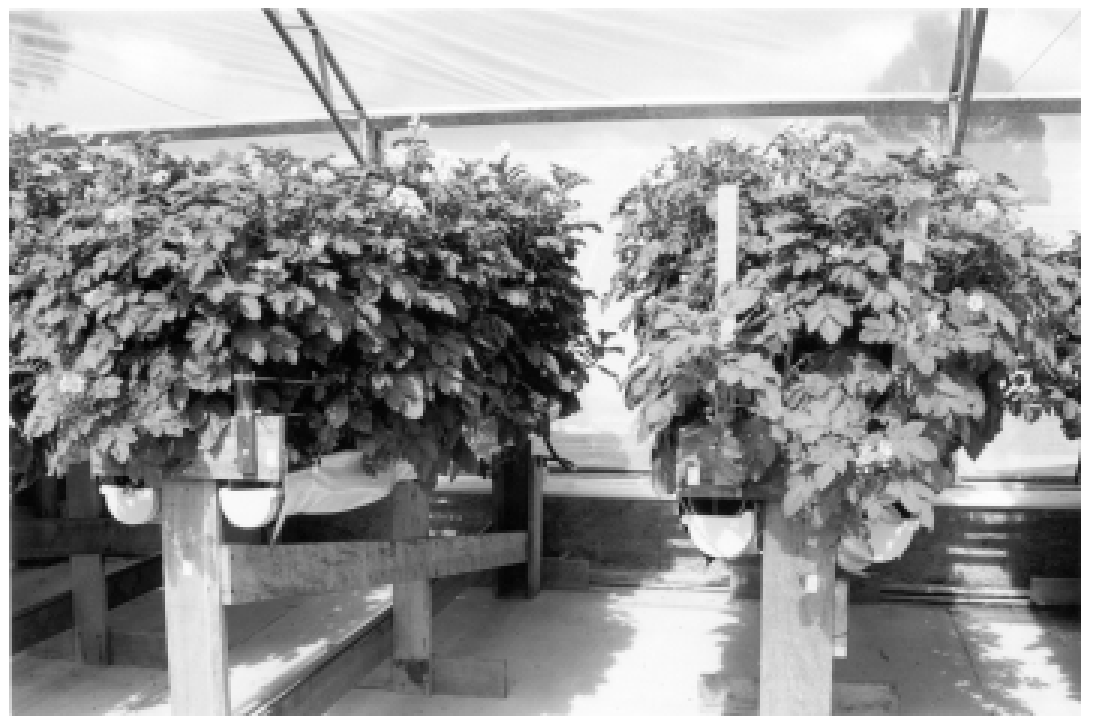

Figura 3. Plantas em fase de florescimento no sistema de calhas 
de igual duração. Em função da menor evapotranspiração no período noturno, esse intervalo pode ser aumentado para 30 minutos, sem que haja redução na produtividade.
O depósito para a solução nutritiva, em fibra de vidro ou plástico, deve ter a capacidade adequada ao número de plantas do sistema. Em razão da grande área foliar das plantas de batata, e da

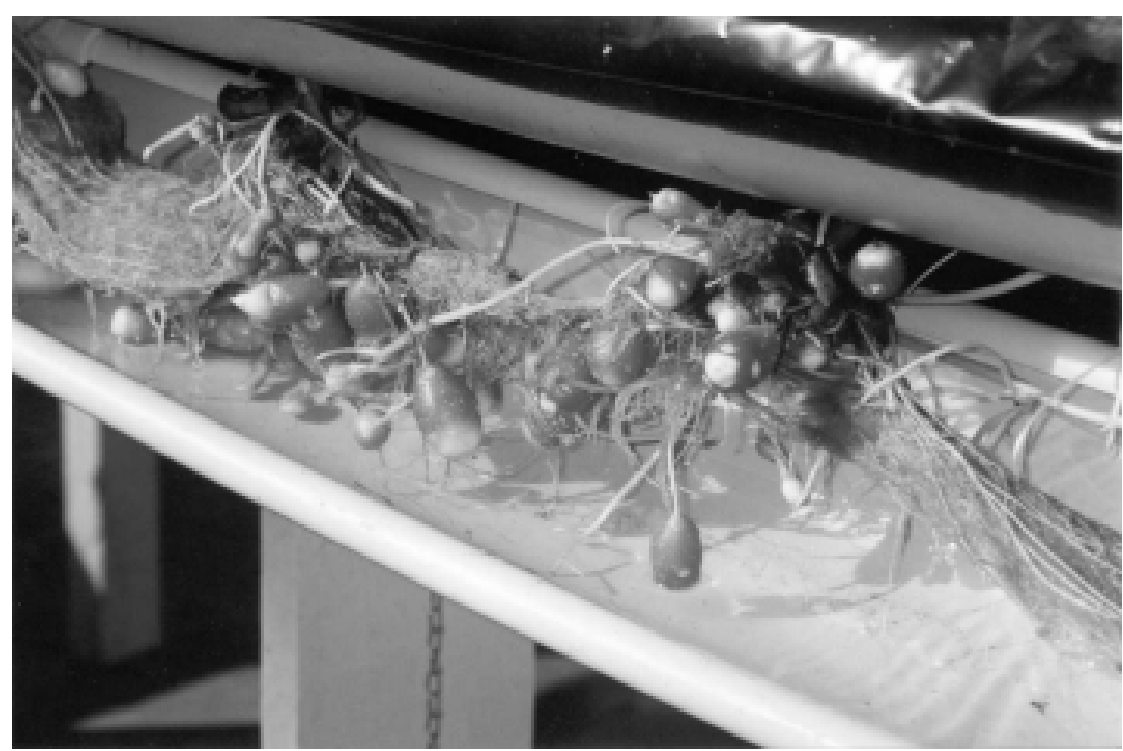

Figura 4. Calha articulada com tubérculos da cv. Baroneza

Tabela 2. Número de tubérculos de duas cultivares de batata produzidos em dois sistemas hidropônicos, em diferentes soluções nutritivas. Pelotas, Embrapa Clima Temperado, 2000.

\begin{tabular}{|c|c|c|}
\hline \multirow{2}{*}{ Soluções } & \multicolumn{2}{|c|}{ Número de tubérculos/planta } \\
\hline & Baronesa & Eliza \\
\hline \multicolumn{3}{|c|}{ Sistema hidropônico em calhas de PVC } \\
\hline $\mathrm{F}$ & 45 a $A^{*}$ & $34 \mathrm{~b} \mathrm{~B}$ \\
\hline $\mathrm{K}$ & $35 \mathrm{~b} A$ & 44 a $A$ \\
\hline \multicolumn{3}{|c|}{ Sistema hidropônico em telhas de fibrocimento } \\
\hline $\mathrm{C}$ & $12^{\star *}$ & 12 \\
\hline $\mathrm{K}$ & 11 & 10 \\
\hline
\end{tabular}

F - Furlani (1998); K - Kristalon Laranja ${ }^{\circledR}$, Nitrato de cálcio Hydro ${ }^{\circledR}$ e Tenso Cocktail®; C - Clark (1982) modificada;

* Médias seguidas da mesma letra minúscula na coluna e maiúscula na linha não diferem estatisticamente pelo teste de Duncan $(\mathrm{P}<0.05)$. (Fonte: Medeiros et al., 2001)

**Diferenças não significativas $(\mathrm{P}<0.05)$. conseqüente alta evapotranspiração sob condições de radiação e temperatura do ar elevadas, deve-se considerar como indicativo do volume do depósito, a necessidade aproximada de dois litros de solução nutritiva por planta. Volumes menores dificultam o manejo do sistema, pela necessidade de freqüentes reposições de solução. Para a irrigação utiliza-se conjunto moto-bomba em que as partes que entram em contato com a solução sejam de PVC ou outro material resistente à oxidação. Nos sistemas descritos trabalha-se com fluxo de solução da ordem de $1 \mathrm{~L} / \mathrm{min}$ em cada calha ou canal.

\section{PRODUÇÃO}

Os resultados obtidos, em relação ao número de tubérculos (Tabela 3), indicam a maior produtividade dos sistemas hidropônicos em relação aos métodos convencionais, onde os índices de multiplicação situam-se entre 3-5 tubérculos por planta (Daniels et al., 2000a). O melhor controle sobre o aporte de nutrientes, é provavelmente o mais importante fator a determinar a obtenção de elevadas produtividades (Caldevilla \& Lozano, 1993).

A comparação entre os sistemas evidencia a maior produtividade do sistema de calhas (Tabela 3), onde a colheita dos tubérculos ainda pequenos, estimula a diferenciação e formação de outros. A energia que seria normalmente utilizada para o aumento do tamanho dos tubérculos, com a eliminação dessa demanda, é carreada para a formação de novo material, propiciando a obtenção de altas taxas de multiplicação. Tal não ocorre na plataforma de telhas, onde o pleno desenvolvimento dos tubérculos, limita a disponibilidade de produtos

Tabela 3. Número médio de tubérculos de batata produzidos por planta em dois sistemas hidropônicos. Pelotas, Embrapa Clima Temperado, 2000.

\begin{tabular}{|c|c|c|c|c|}
\hline \multirow{4}{*}{ Sistema } & \multicolumn{4}{|c|}{ Cultivar } \\
\hline & \multicolumn{2}{|c|}{ Baronesa } & \multicolumn{2}{|c|}{ Eliza } \\
\hline & \multicolumn{4}{|c|}{ Material propagativo } \\
\hline & Tubérculo & Plântula & Tubérculo & Plântula \\
\hline Calha de PVC & $49,6 \mathrm{aA}^{*}$ & $32,4 \mathrm{aB}$ & 32,9 aA & 23,0 aA \\
\hline Telha de fibrocimento & $21,0 \mathrm{bA}$ & 10,9 bB & $13,5 \mathrm{bA}$ & 8,6 bA \\
\hline
\end{tabular}

*Médias seguidas da mesma letra minúscula na vertical e maiúscula na horizontal não diferem entre si pelo teste Duncan $(\mathrm{P}<0,05)$. (Fonte Pereira et al.,2001) 
Tabela 4. Peso médio de tubérculos de batata produzidos em dois sistemas hidropônicos. Pelotas, Embrapa Clima Temperado, 2000.

\begin{tabular}{|c|c|c|c|c|}
\hline \multirow{4}{*}{ Sistema } & \multicolumn{4}{|c|}{ Cultivar } \\
\hline & \multicolumn{2}{|c|}{ Baronesa } & \multicolumn{2}{|c|}{ Eliza } \\
\hline & \multicolumn{4}{|c|}{ Material propagativo } \\
\hline & Tubérculo & Plântula & Tubérculo & Plântula \\
\hline Calha de PVC & $3,3 \mathrm{bA}^{*}$ & $3,8 \mathrm{bA}$ & $4,5 \mathrm{Ba}$ & $4,9 \mathrm{bA}$ \\
\hline Telha de fibrocimento & $12,9 \mathrm{aA}$ & $14,8 \mathrm{aA}$ & $15,4 \mathrm{aA}$ & $14,1 \mathrm{aA}$ \\
\hline
\end{tabular}

*Médias seguidas da mesma letra minúscula na vertical e maiúscula na horizontal não diferem entre si pelo teste Duncan ( $\mathrm{P}<0,01)$. (Fonte Pereira et al., 2001)

fotossintéticos para a formação de novo material. Nesse sistema, com a colheita realizada ao final do ciclo da cultura, o peso médio dos tubérculos é sempre maior, se comparado ao sistema anterior (Tabela 4).

Deve ser salientado, na comparação de produtividade entre os sistemas, que as características de manejo das calhas de PVC, onde para a colheita deve-se ter acesso a cada calha individualmente, aumenta o espaço necessário para o sistema, o que faz com que o número de plantas por unidade de área, seja menor em comparação à plataforma de telhas de fibrocimento.

Ambos sistemas podem utilizar plântulas ou minitubérculos como material propagativo. Observa-se, no entanto, que a taxa de multiplicação é maior quando são utilizados minitubérculos (Tabela 3).

\section{LITERATURA CITADA}

CALDEVILLA, E.M.; LOZANO, M.G. Cultivos sin suelo: hortalizas en clima mediterraneo. Reus, Espanha: Ediciones de horticultura. 1993. 123 p. CHANG, D.C.; KIM, S.Y.; HAHM, Y.; SHIN, K.Y. Hydroponic culture system for the production of seed tubers without soil. American Journal of Potato Research, v. 77, n. 6, p. 394, 2000.
CLARK, R.B. Nutrient solution growth of sorghum and corn in mineral nutrition studies. Journal of Plan Nutrition. v. s, n.8, p. 1039-1057. 1982.

DANIELS, J.; PEREIRA, A.S.; FORTES, G.R.L. Verticalização da produção de batata-semente por produtores de agricultura familiar no Rio Grande do Sul. Pelotas: Embrapa Clima Temperado, 2000a, 4 p. (Comunicado Técnico).

DANIELS, J., SILVA, A.C.F.; SOUZA, Z.S. Degenerescência da batata-semente nas principais regiões produtoras dos estados de Santa Catarina e do Rio Grande do Sul. In: REUNIÃO TÉCNICA ANUAL DE PESQUISA E EXTENSÃO DA CULTURA DA BATATA DA REGIÃO SUL DO BRASIL, 7., 2000, Curitiba. Resumos ... Curitiba: IAPAR, 2000b. p. 39.

FORTES, G.R.L.; ROOS, F.C.; FLORES, R.; DANTAS, A.C.M. Multiplicação in vitro de batata (Solanum tuberosum L.) em meios semi-sólido e líquido com diferentes concentrações de sacarose. Pelotas: Embrapa Clima Temperado, 1998, 5 p. (Pesquisa em Andamento).

FURLANI, P.R. Instruções para o cultivo de hortaliças de folhas pela técnica de hidroponia NFT. Campinas: IAC, 1998. Bop. (Instituto Agronômico. Boletim Técnico, 168).

LE HINGRAT, Y.; MARHIC, J.V. Development of hydroponical culture for large-scale production of healthy tubers. In: TRIENNIAL CONFERENCE OF THE EUROPEAN ASSOCIATION FOR POTATO RESEARCH, 14., 1999, Sorrento, Itália. Abstracts...Sorrento: Assessorato Agricoltura Regione Campania, 1999. p. 54-55.
MARTÍNEZ, C.F.; ALVAREZ, J.R.D. Cultivos sin suelo. La Mojonera, Espanha: Instituto de Estudos Almerienses, FIAPA, 1993. 372 p.

MEDEIROS, C.A.B.; SILVA, E.S.B. Produção de sementes pré-básicas de batata em sistemas de cultivo sem solo. Horticultura Brasileira, Brasília, v. 17, n. 3, p. 300, 1999. Resumo.

MEDEIROS, C.A.B.; DANIELS, J.; PEREIRA, A.S. Produção de sementes pré-básicas de batata em sistema hidropônico: Multiplicação a partir de plântulas produzidas in vitro. Horticultura Brasileira, Brasília, v. 19, Suplemento CD-Rom, 2001a. MEDEIROS, C.A.B.; DANIELS, J.; PEREIRA, A.S. Produção de sementes pré-básicas de batata em sistema hidropônico: Multiplicação a partir de minitubérculos. Horticultura Brasileira, Brasília, v. 19, Suplemento CD-Rom, 2001b.

MEDEIROS, C.A.B.; DANIELS, J.; PEREIRA, A.S. CORRENT, A.R. Avaliação de soluções nutritivas na produção de sementes pré-básicas de batata em sistema hidropônico. Horticultura Brasileira, Brasília, v. 19, Suplemento CD-Rom, 2001.

PEREIRA, J.E.S.; MEDEIROS, C.A.B.; FORTES, G.R.L.; DANIELS, J.; PEREIRA, A.S. Avaliação de dois sistemas hidropônicos para a produção de sementes pré-básicas de batata. Horticultura Brasileira, Brasília, v. 19, Suplemento CD-Rom, 2001.

ROMANENKO, G.A. Brasil e Rússia - A união faz a força na agricultura e na biotecnologia. Biotecnologia. Brasília, n. 2, p. 30-33, 1997. Entrevista. 